This is an electronic reprint of the original article. This reprint may differ from the original in pagination and typographic detail.

Author(s): Lähdesmäki, Tuuli

Title: $\quad$ Politics of affect in the EU heritage policy discourse : an analysis of promotional videos of sites awarded with the European Heritage Label

Year: $\quad 2017$

Version:

Please cite the original version:

Lähdesmäki, T. (2017). Politics of affect in the EU heritage policy discourse : an analysis of promotional videos of sites awarded with the European Heritage Label. International Journal of Heritage Studies, 23(8), 709-722.

https://doi.org/10.1080/13527258.2017.1317649

All material supplied via JYX is protected by copyright and other intellectual property rights, and duplication or sale of all or part of any of the repository collections is not permitted, except that material may be duplicated by you for your research use or educational purposes in electronic or print form. You must obtain permission for any other use. Electronic or print copies may not be offered, whether for sale or otherwise to anyone who is not an authorised user. 


\section{Politics of Affect in the EU Heritage Policy Discourse: An Analysis of Promotional Videos of Sites Awarded with the European Heritage Label}

\section{Tuuli Lähdesmäki}

Department of Music, Art and Culture Studies, University of Jyväskylä, Jyväskylä, Finland

Postal address: Department of Music, Art and Culture Studies, P.O. Box 35, 40014 University of Jyväskylä, Finland

Tel: +358048053839

E-mail: tuuli.lahdesmaki@jyu.fi

Tuuli Lähdesmäki (PhD, DSocSc) is Research Fellow and Adjunct Professor working at the Department of Music, Art and Culture Studies, University of Jyväskylä, Finland. Lähdesmäki's current research projects are funded by the Academy of Finland (European Cultural Heritage in the Making: Politics, Affects and Agency, EUCHE) and the European Research Council (Legitimation of European Cultural Heritage and the Dynamics of Identity Politics in the EU, EUROHERIT). 


\title{
Politics of Affect in the EU Heritage Policy Discourse: An Analysis of Promotional Videos of Sites Awarded with the European Heritage Label
}

\author{
European cultural heritage is discussed with affective rhetoric in current European Union \\ (EU) policy discourse. How does affect contribute to the meaning-making of a European \\ cultural heritage and how are the workings of affect used by the EU to promote certain \\ meanings of heritage and effect thereupon? The analysis focuses on recent promotional \\ videos of sites awarded with the European Heritage Label by the EU. In the videos, \\ affective textual, visual, audible, and narrative tropes intertwine with the tropes of EU \\ policy rhetoric, increasing its capacity to impact and 'move' the receivers. The ethos of a \\ European cultural heritage in the videos is based on a paradox: the history of the several \\ sites is in various ways intertwined with extreme agony, violence, hatred, oppression, and \\ injustice. However, the stories of the sites in the videos turn their legacy into a positive \\ ethos of conquering these negative extremes and cherishing their positive opposites: \\ freedom, justice, solidarity, and peace. The affectivity of the videos prepares the receivers \\ to adopt their political aim: support for the EU and European integration. The analysis \\ indicates how affect has a key role in producing an impression of the irrefutability and \\ choicelessness of EU politics.
}

Keywords: affect; cultural heritage; European Heritage Label; European Union; politics

\section{Introduction}

The idea of heritage has become more and more problematic in today's Europe characterized by two opposing trajectories. On the one hand, the increasing cultural pluralism and hybridity, global cultural flows, and movement of people within and across borders challenge the traditional nationalist and Euro-centric meanings of heritage and the ways of fostering them in Europe. On the other hand, the increasing nationalist and populist movements in Europe have politicized the ideas of national and European heritage in new ways (Lähdesmäki 2015). In the discourses of these movements, heritage is commonly considered as a cornerstone of monocultural nation-building projects and a continuation of primordial roots of national or ethnic communities in Europe. The recent political, economic, social, and humanitarian crises in Europe have shaken the very foundations of the European Union (EU) and raised criticism towards the European integration process and the legitimacy of the EU. Simultaneously, the 
idea of shared cultural roots, memory, and heritage has gained an important role in EU politics and policies. The EU's increased interest in a common European heritage and a common European narrative and its various initiatives and projects seeking to promote them can be perceived as the EU's means to respond to and as an attempt tackle some of these recent crisesincluding identity crises - in Europe. Indeed, cultural remembrance, historical memory, and the idea of heritage have become a powerful vehicle for mobilizing a European identity and shaping the EU's identity politics (Littoz-Monnet 2012).

Culture is budgetarily a tiny EU policy sector and the EU does not have the same legal authority in it as in policy sectors at the core of the union. It has, however, a crucial function in the production of images, impressions, cultural meanings, sentiments, and emotional bonds. The current EU policy rhetoric about a sense of belonging to the EU, a European identity, and common heritage as their basis seeks to influence European citizens on the emotional and affective level. In current EU policy discourse, the idea of heritage itself includes various positive, affirmative, and uplifting features and is discussed with affective rhetoric. EU policy discourse has a strong 'poetic dimension' (Banús 2015) in its eloquent emphasis on culture, heritage, and identity. This poetic dimension brings to EU policy discourse lofty and idealistic tones that lift the meanings of the discourse above everyday and political decision-making, thereby seeking to naturalize its claims. This is precisely the reason why the poetic dimension of EU policy discourse is extremely important for the EU. It is also the reason why it is essential to take it into closer examination to attain a more critical understanding of the EU's current 'European project'. As public debate on the current state of the EU and Europe is full of economic and political analysis and 'hard' data and arguments, the study of the 'soft', cultural aspects of the EU's European project and 'being European' is crucial (Sassatelli 2015).

In this article, I focus on the affective dimension in the EU's attempts to create a common European cultural heritage. The background of the article stems from my long-term research on EU cultural and heritage initiatives and my observations as a researcher and my personal experiences as a visitor to various sites that the EU has officially labeled as European cultural heritage. These sites, and the way their story is told in diverse informational and promotional material, are 'moving' in both meanings of the word. They touch the receivers at the affective level and the moment of 'being moved' produces diverse responses that may range from bodily reactions to an awakening of thoughts, perceptions, and opinions. Becoming 'moved' by the 
stories of the sites may happen regardless - or even in spite of - a critical or resistant attitude towards meanings they convey (cf. Golańska 2015, 774).

The aim of this article is to analyze the politics of affect in EU heritage policy discourse. I ask: How does affect work and how are its workings used in making a European cultural heritage, and how and why are the workings of affect utilized as politics in EU heritage policy discourse? The empirical analysis of the article focuses on the most recent EU heritage initiative - the European Heritage Label - that was launched as the EU's new flagship initiative in the field of heritage in 2011. The European Commission, on its official web site, presents the European significance of the labeled sites and their story as European cultural heritage. Besides a general introduction to the initiative, the web site also includes promotional videos of all sites. These videos form a multimodal, official narrative of a European cultural heritage and bring to the fore the politics of affect at work.

The article seeks to respond to several needs in recent scholarly discussion: a need for further study of the 'soft', cultural aspects of 'being European' and of possessing a European identity; a need for critical understanding of the poetic dimension of EU policy discourse; and a need for a deeper analysis of the workings of affect in heritage studies. In addition, the article aims to develop a methodology for analyzing the affectivity and politics of affect in multimodal data and broaden the scope of EU research. The interdisciplinary study of the article utilizes concepts and theoretical approaches from affect theories and social semiotics and combines theoretical discussions from the fields of critical heritage studies, cultural policy research, visual culture studies, and European studies.

\section{Affect, Heritage, and Politics - An Intertwined Conceptual Triad}

Affects, emotions, and feelings have been broadly discussed in recent cultural theory in general and in feminist epistemology and esthetics in particular. This discussion includes various theoretical views on the conceptualization of affect and contradictory definitions of it. My approach to affect in this article stems from criticism towards Non-Representational Theory's notion of affect as something that is prior to cognition, apprehension, or emotion, and as a biologically based process not mediated by representation, culture, or discourse (Wetherell 2012; Smith and Campbell 2015). In these critical views, affect is not separated from cultural, 
social, and discursive meanings. Indeed, a broad body of literature on affect emphasizes the interconnected and interactive nature of affect and signification/discourse (Connolly 2002; Ahmed 2004a, 2004b, 2004c; Blackman and Venn 2010; Wetherell 2012) and affect and cognition/reason (Reddy 2001; Ahmed 2004a) rather than perceiving them as distinct systems. Following these views, affect is treated in this article as closely intertwined with cognition and culturality and discursivity of a meaning-making process.

A crucial question that Grossberg $(1992,1997)$ has emphasized in the discussion on affect is how to adapt the concept and its theoretical realm for use in empirical analysis of diverse cultural phenomena. What is needed is a perception of the mediating elements that function between affective and cognitive levels and through which their interaction and the workings of affect can be analyzed (Pruchnic and Lacey 2011). In art and literary studies, scholars have analyzed the affectivity of works of art — their capacity to invoke affect — by exploring ideas transmitted by the content of art works; by examining the style, mode, and other textual/visual esthetic practices of art works; and by focusing on the materiality of art (see for example, Sedgwick 2003; Riley 2005; O'Sullivan 2006). In empirical studies, it has also been common to follow Ahmed's (2004a, 2004b, 2004c) theorization of affect and emphasize how particular objects, images, and signs become invested with affect because of historical, as well as cultural reasons (see Rumi 2015). Ahmed has called these intense elements of attachment 'sticky objects of emotion'. These sticky objects are saturated with affect and they invoke emotions that 'circulate' in a collective and align individuals with a collective, such as a nation.

Although affect it not reducible to language and linguistic practices, the extra-discursive nature and the 'bodily matter' of affect can be explored via language and texts, as Rumi (2015) argues. Indeed, the only way to operationalize the concept of affect for cultural analysis, or to simply think affect, is through language (Laurier and Philo 2006; Wetherell 2013; Golańska 2015). In her analysis, Ahmed (2004a, 13) emphasizes 'the emotionality of texts' that is 'one way of describing how texts are "moving", or how they generate effects'. For Ahmed, 'figures of speech' are crucial to the emotionality of texts. The approach of this article relies on these recent art and literary studies, in which affectivity is analyzed through repeated and emotionally charged 'sticky' elements - in Ahmed's terms - that mediate and transmit affect between precognition and cognition. 
Scholars in heritage studies (Gregory and Witcomb 2007; Crang and Tolia-Kelly 2010) have seen heritage as a juncture that enables and arrests circulation of objects, places, identities, ideas, and emotions. However, affect and emotion have been avoided in scholarly discussions of heritage and museums until relatively recently, or are still neglected, as several scholars note (Smith and Waterton 2009; Crang and Tolia-Kelly 2010; Smith, L. 2011; Waterton and Watson 2013; Waterton 2014; Smith and Campbell 2015). During the past decade, moments of 'being moved' by heritage and questions that relate to the tactile, experiential, aural, emotional, and sonic dimensions of heritage, however, have been put forward in studies on objects of remembrance, heritage, and historical sites saturated with emotionally charged interpretations of the past. For example, scholars have explored how emotion has contributed to pedagogy within the work of museums and heritage sites (Gregory and Witcomb 2007; Soren 2009) and have examined the emotional response of visitors through diverse and methodologically flexible audience reception studies (Poria, Butler, and Airey 2003; Bagnall 2003; Poria 2007; Smith, L. 2011; Smith, R. 2015; Waterton and Watson 2015). In these studies, the main focus is on representations of affects, experienced emotions, and their registers rather than the capacity of affect to impact, have consequences, and bring about action in the realm of the political.

The capacity of affect to generate action brings out a link between affect and politics. The affect may come upon us unexpectedly, as is often asserted in theoretical discussions on affect (Ahmed 2004a; Thrift 2008), but it does not mean that affective moments are always unexpected and that they cannot be sought, regulated, or managed (Smith and Campbell 2015). Affects can be 'planned' and aimed to be intentionally generated since they may bring about moral and political consequences and impacts (Smith and Campbell 2015). Indeed, affect should be taken seriously because it enables an exercise of power; affect can be an object of engineering deployed politically for political ends (Thrift 2004). In contemporary societies, affect is engineered as a whole infrastructure of feeling and promoted with 'affective technologies' widely utilized in both commercial and political spheres (Thrift 2008). Multimodal streams on the Internet, such as online videos made to reach a broad audience, are perfect examples of current affective technologies used by political, commercial, and civic actors in the contest for attention, impact, and power. My approach to affect in this article emphasizes the capacity of affect to activate and become political. 


\section{Context, Data, and Methods}

During the past 15 years the EU has launched several initiatives aiming to foster the idea of a common European cultural heritage. The newest of these initiatives is called the European Heritage Label. In this initiative, the European Commission annually awards official labels to sites on the basis of their applications. The labeled sites are first pre-selected by a national panel and an international expert panel appointed at the EU level makes the final selection. The selection criteria require that 'the sites for the label must hold a symbolic European value and must have played a significant role in the history and culture of Europe and/or the building of the union' (EC 2015). The first four sites were labeled in 2014, the next 16 sites got the label the following year, and the latest nine sites were labeled in 2016. Altogether 24 Member States have announced their participation in the initiative.

The only public forum in which the EU is able to display these sites and their European dimension is the official web site of the European Commission. Indeed, the Commission's web site is the only public forum for the EU to communicate the cultural meanings of Europe, since there is no common European public sphere or other European-wide channels of communication for this purpose. The Official Journal of the European Union-available online and in all official EU languages - brings to the fore the official compendium of EU legislation and other official documents of the EU's institutions, bodies, and agencies. As an opposite of the legislative communication mode and bureaucratic rhetoric used in the journal, the Commission uses a more 'accessible' and appealing communication mode on its web site.

The European Commission has recently made an effort to promote the idea of a common European cultural heritage on its web site. Besides images and introductory texts, the European Heritage Label sites are presented through videos published after an annual award ceremony. To analyze the workings of affect in EU heritage policy discourse, all 20 videos that were available at the Commission's web site (EC 2016) in spring 2016 were selected for analysis. These videos last approximately four minutes and are created by the same media company commissioned by the European Commission. The videos are structured in a similar pattern. Each video starts and ends with a logo of the label. Through landscape scenes the videos focus on the building(s) at the labeled site where a local expert or experts - whether directors or other leading experts of the sites or mayors of the cities - introduce what the sites are about and describe their significance as a European cultural heritage. The videos display both the current 
state of the sites and their history, for example, through historical models of the sites; old works of art, photographs, and video clips; and/or preserved and musealized objects or archived documents. At the end of the videos the focus is typically on various contemporary audiences visiting the sites, and some videos also include short comments from the visitors about the meaning of the site to them. In half of the videos the people talk in English; other languages are translated into English in subscripts.

My analysis focuses on the politics of affect mediated by these 20 videos as audiovisual text and discourse - not on the 'factual' actions, emotions, or intents of the individuals performing in the videos nor those of the individuals who have proposed, screen-written, filmed, and edited the videos. The analysis approaches affect produced by the videos as a transpersonal experience that is 'moving' and has the capacity to activate; thus the politics of affect cannot be simply narrowed to the political intents of the actors in or behind the videos.

The analysis is guided by the main research question on the politics of affect at work and the theoretical point of view of the intertwined nature of affect and meaning/discourse. Methodologically the analysis relies on some key starting points in social semiotics in which modes of communication are explored within and as a part of a particular social setting and based on historically specific and socially and culturally shared 'semiotic resources' (Leeuwen 2005). In the analysis, the videos are approached as a social semiotic system that enables the negotiation of power relationships and functions as the means for articulating ideological positions (cf. Kress and Van Leeuwen 2006). In social semiotics, power and ideologies are perceived as 'meaning potentials' included in all sign systems, that is, they are the possible meanings which may be activated by the producers and receivers of signs (Jewitt and Oyama 2001). Following the key aims of social semiotics, the article engages in the investigation of semiosis 'in use', the contest for power, and the articulation of ideology and combines these analytical interests with the investigation of the politics of affect.

The videos were analyzed by focusing on the 'transmission of affect' - a conceptualization introduced by Brennan (2004) and further discussed by Thrift (2008) with the concept of 'affective contagion' and an idea utilized by several scholars in their empirical analysis of political texts, literature, and other cultural phenomena (Kølvraa 2015; Smith, R. 2015). With conceptualization Brennan (2004) refers to a process in which the emotions and affects of one person, and the energies these affects entail, can enter into another. For Brennan, the origin of 
the transmitted affects is social, as they do not only arise within a particular person but also emerge in an intertwined interaction with other people and an environment. Cultural products enable the transmission of affects entailed in and mediated by their semiosis - both at the level of content and mode of expression (cf. Deleuze 1997). Thus, affects are not (only) represented in the contents of cultural products; they emerge, stick, transmit, and mediate in the reception of their semiotic substance and culture-related esthetics.

Methodologically my analysis of the data proceeded via phenomenological reading of 'emotionality of texts', as Ahmed (2004a, 12-13) describes her methods of analysis. Following Ahmed's and Rumi's (2015) methodological approach, my analysis started from close reading (Brummett 2010) of the textual, visual, and audible signs in the videos and identifying affective textual, visual, audible, and narrative tropes repeated in them. Secondly, the analysis focused on identifying affective rhetorical tropes common in the EU policy discourse repeated in the videos. Thirdly, through close reading of the data I sought to perceive the connectedness and interaction of these tropes. The term 'trope' is used in the analysis to refer to the use of figurative language and commonly recurring literary and rhetorical devices and motifs that can also be visual and audible (cf. Rumi 2015). To ensure the systematism of the analysis and to ease the analysis of the connectedness and interaction of the tropes, Atlas.ti was utilized as tool to arrange the findings of the close reading. The videos were treated in the analysis as an affective entity through which the EU communicates about the idea of a common European cultural heritage. The following section presents the affective textual, visual, audible, and narrative tropes identified from the videos.

\section{Affective Tropes in the Meaning-Making of a European Cultural Heritage}

\section{Textual Tropes}

My analysis of the affectivity of the videos starts from analysis of textual 'figures of speech' and words that are invested with affect due to the historical and cultural contexts intertwined in them and drawn forth by them. The speech of the narrators in the videos is filled with these kinds of textual tropes that - in the visual, audible, and narrative context of the videos - have an affective appeal and seek to invoke an emotional response. The most repeated affective textual tropes in the videos are related to a 'struggle vocabulary' used to describe historical 
conflicts taken place at the site and to depict the significance of the sites in solving diverse conflicts. 'Sticky' words, such as 'war', 'conflict', 'struggle', 'revolt', 'fight', 'enemy', and 'victim', saturated with affective and emotional meanings, recur in the narrators' speech and depict the past of Europe as a war-like, violent, and unstable state cut by various lines of tension between different groups of Europeans.

The struggle vocabulary is used in 15 videos and it forms a recurring affective starting point for delineating the idea of a European cultural heritage in them. In many of these videos the story of the site starts from a brief description of struggles and conflicts of the past. For example, the narrator in the video of the Hambach Castle (Germany) describes the initial historical situation of the site as follows: 'Living conditions were difficult due to customs, duties, and poor harvests. So people tried to revolt against the oppression ${ }^{1}$ by the authorities' (1:21-1:36); the narrator in the video of the Kaunas of 1919-1940 (Lithuania) starts the video by stating: 'The Kaunas city is located in the center of Lithuania. Kaunas was temporarily the capital because our main capital, Vilnius, were occupied'2 (0.23-0:35); and the narrator in the video of the Franja Partisan Hospital (Slovenia) depicts the starting point in the story of the site by stating: 'Partisan hospitals were a Slovenian particularity. The hospital was built by the members of the Partisan Army who fought against fascism and Nazism during the Second World War here in Slovenia' (0:38-0:56).

Although the 'struggle vocabulary' in the videos forms the affective basis on which the story and meanings of the sites as a European cultural heritage are commonly being constructed, the negativity of this affective basis is sought to be made positive by using a recurring 'conciliation vocabulary' to describe the later phases or 'achievements' of the sites. Indeed, recurring 'sticky' words, such as 'peace', 'peaceful process', 'peaceful cooperation', 'peaceful transformation', 'peace-making', 'building relations', 'arbitration', 'negotiation', 'reconciliation', and 'solidarity', appealing to a sense of justice and respect for conquering the horrors of war, form a counter trope to the negatively charged words in the videos. In 13 videos, the narrators present the historical significance of the sites in terms of promoting reconciliation and peace-making in Europe. Struggle and conciliation, war and peace, form an affective object whose extremes are closely connected: the latter prerequisites the former. Treating these two textual tropes as intertwined enables investing the past of Europe with more conciliatory and amicable interpretations. In the videos, the European history of wars is turned into a history of peacemaking. As the narrator in the video of the Sites of the Peace of Westphalia (Germany) states: 
It was in the Peace Hall of our historic town hall that the Peace of Westphalia was negotiated. This is where the envoys of the various territories and powers met and where, in 1648, after five years of negotiations, peace was finally achieved. Osnabrück is home to the German Foundation for Peace Research and the Federal Environmental Foundation, thus contributing, in a broad sense, to reconciliation in Europe and worldwide, not only regarding the struggle for resources, but also the peaceful co-existence of the various religions. (1:27-2:05)

In addition to struggle and conciliation, the affectivity of the text in the videos is commonly manifested in a vocabulary of 'generational continuity'. In nine videos, the narrators bring out children, young people, students, or future generations and the importance of transmitting and mediating information and understanding of the past to the future. As the narrator in the video of the Pan-European Picnic Memorial Park (Hungary) states:

I think that now our role is to explain the events of that time to the young people of today. To make them understand what it meant to be locked behind the Iron Curtain. It's important. When us organizers created the Pan-European Picnic Foundation, the goal was to maintain and pass on historical accuracy, since today, neither those 26 years ago, nor the generation now in its thirties can remember those times. (1:48-2:35)

The emphasis on learning from past mistakes and strengthening the continuity of learned lessons functions as an affectively charged invitation to the receivers of the videos to join in a project of transmission of a common heritage and the values attached to it.

Ahmed (2004a, 13) has investigated the 'emotionality of texts' in terms of the way in which texts name different emotions. The narrators in the videos name an emotion only a few times. Most commonly (in the four videos) they state being 'proud' of their site and its history and the values it seeks to promote. The abstention from naming emotions reflects the convention of the genre of the videos: a matter-of-fact and factual talk creates an impression of the objectivity and seriousness of the videos as documentaries. However, the documentary genre of the videos and its effect of creating an impression of 'keeping to facts' enforce the affectivity of the videos; they present the affective stories of the past 'as they happened' and 'as truths', not colored with named emotions. 


\section{Visual Tropes}

Text as written language is governed by different logic than are images and visual communication. As Kress (2003) and Kress and van Leeuwen (2006) note, written text is structured by the logic of time and temporal sequences, while images are governed by the logic of spatial relations and simultaneity. In visual images, the position, size, and composition of the contents of the image play a significant role in meaning-making (Liu 2013). In spite of the divergent logic of text and image, in both cases their meanings arise from the way different textual or visual elements are arranged, connected, and integrated. The videos of the heritage sites compose their visual narrative from various elements: graphic images, landscape and architectural scenes, works of art, old photos and video clips, and different kinds of scenes of people. The videos utilize several emotionally charged images that have the capacity to 'move' the receiver, both alone and when connected to textual, audible, and narrative elements.

All the videos start and end with the same audiovisual graphics: the logo of the European Heritage Label, composed of five rock-like pieces of different colors, leaving a white starshaped area between them, appears on the screen followed by the text of the logo. While the text appears on the screen, the star in the logo pulses three times. The simultaneous sound of a heartbeat in the soundtrack of the videos brings a living body to the reception event. The pulsing logo prepares the receivers for the emotionality of the videos and concludes the viewing event by underlining bodily reactions and bodily felt feelings produced by the video just seen. The viewing of the videos becomes a lived-through event and invests the idea of heritage with a meaning of a 'living' process. The heartbeat of the logo emphasizes the affectivity of heritage in general and a European cultural heritage in particular, and presents the EU as a caring and emotionally involved administrative body interested in the emotional attachments of Europeans. At the end of each video the pulsing logo of the label is followed by the logo of the European Commission.

The videos are filled with numerous images invested with an affective appeal in the context of the videos ranging from people to historical artefacts and from architectural spaces to nature. The people who are displayed the most in the videos are the expert narrators. In the mid-shots and close-ups, their bodily and facial expressions seek to convince the receivers of the 
importance of the sites and their history and thereby create an impression of heritage as 'a serious matter'. Besides the expert narrators, 12 videos include various mid-shots and closeups of children, youths, or young adults/students who are visiting the sites. Their faces express an interest in and a concentration on what they are watching or hearing; their visible emotions range from being touched to happiness. The affectivity of the bodily expressions of the people in the videos are meant to impact the receivers; the expressions indicate how a European cultural heritage 'moves' people. The videos present heritage as an issue that is not faced halfheartedly or carelessly.

Besides displaying living people, eight videos include mid-shots and close-ups of archival photos or video clips. In the case of Residencia de Estudiantes (Spain), these images depict notable European cultural and scholarly figures, and in the case of Robert Schuman's House (France) and Museo Casa De Gasperi (Italy), the so-called founding fathers of the EU. The serious faces and bodily expressions of these figures reflect the serious tone of the stories recurring in the videos. Particularly the mid-shots and close-ups of old photos and videos from WWII and the struggle against Communist oppression are charged with affect in the context of the videos. Besides their matter-of-fact content, these images entail to their reception the historical and cultural contexts of the remembrance of their victims in national and global public and historical memory. The topic of the struggle for freedom and its loss is most powerfully depicted in images where a young girl blankly gazes at the receiver from a crack in the door of a train heading from Camp Westerbork (The Netherlands) to a concentration camp; in images of a crying child and a panicking crowd rushing through an open gate to freedom at the Hungarian-Austrian border in 1989; and in video clips from a struggle of the Polish Solidarity movement displaying crying faces, shooting, beating, and arresting of people, and demonstrating and cheering crowds. In the visual narration of the sites, the images of the feelings of individuals and of groups vary, fixing the individual feelings to collective experiences.

The photos and video clips invoke an impression of the authenticity of the past experiences and the presence of history and its emotionality 'as it happened'. In the videos, the affectivity of images is, however, also present through works of art depicting human figures. The bodily and facial expressions in works of art may lose in their impression of authenticity to photos and video clips, but they are able to invoke strong emotional attachment. Indeed, art is a 'natural' place to encounter affect; the esthetic power of art functions as a recourse to affect, as 
O'Sullivan (2001) notes. In 11 videos, the affective textual and narrative tropes are connected to mid-shots or close-ups of sculptures or paintings of human figures that strengthen their effect. For example, in the video of the Abbey of Cluny (France), close-ups of chipped and nose-less faces of medieval stone sculptures depict the narration of Cluniac monks who promoted the Pax Dei movement seeking to prevent fighting on Sundays, and in the video of Camp Westerbork, close-ups of a contemporary bronze sculpture depicting a group of haggard people is connected to a wish of a survivor to avoid massacres in the future and the narrator's appeal that 'the European Union should convey the message that these places, no matter how bleak they may be, also play a role in Europe's history' (3:09-3:18).

The logic of spatial relations and proportions has an important role in the politics of affect in the videos. In 18 videos, the buildings at the labeled sites are viewed from a low angle that emphasizes their size, impressiveness, and power. Views of the skillfully decorated and lavish interiors of the old buildings invoke an impression of grace and preciousness. This kind of spatial logic of visuality in the videos strengthens the uplifting effect of the textual tropes of 'conciliation' and 'peace'. At the same time, this logic forms a contrast to the struggle vocabulary and images of conflict recurring in the videos. This contrast contains the potential to uplift the struggle and depict nobility in it.

The images of buildings and their architectural details in 11 videos and close-ups of old archival documents in nine videos concretize and materialize the idea of heritage in them. These material, preserved, and/or musealized objects function as 'sticky objects' due to their aura of authenticity; they are presented as evidence of the past time and witnesses of its events. The idea of passing time and authentic objects as its witnesses is even strengthened when they are contrasted with images of children and youths of the present day. Images of children and youths visiting the sites are used in 15 videos.

The visual narration in the videos connects the buildings at the sites to the surrounding environment. All the videos start from rural or urban landscape scenes from which the videos focus on the buildings of the sites. In nine videos, the view is also focused on some natural details, such as leafless branches and raindrops. The weather and the season when the videos have been filmed have an impact on the emotionality of the images in them. All the videos have been filmed during a leafless season, and in 12 videos the landscape scenes are either completely or partly filmed in rainy, windy, or foggy weather, enabling the emergence of a 
melancholic affect and strengthening the emotional reception of the videos. The season and weather in the videos are a part of their affective esthetics, emphasizing their effect. This esthetics is consistent with, and strengthens the effect of, the 'struggle vocabulary' that is repeated throughout the videos.

\section{Audible Tropes}

The calm and smooth voice of the expert narrators is the key audible element drawing the attention of the receivers of the videos. The stories told by the narrators are enlivened with various subtle sounds, such as a distant ripple of conversation, voices of children, a rustle of archive documents, and various sounds of nature, such as the pitter-patter of rain, a bird song, and the babble of running water.

The most affective audible trope in the videos is, however, the music that is used throughout all of them. Like art, music has a long-known capacity to raise affect and impact receivers at the non-cognitive level (Thompson and Biddle 2013). The soundtrack during the appearance of the logo of the European Heritage Label at the beginning of the videos is composed of a short melody of classical music. The delicate melody ends with high tones played by stringed instruments. The soundtrack draws forth the historical and cultural contexts of European classical music with impressions of traditionality, high culture, exclusiveness, and sophistication. The soundtrack places the receivers into the 'right' mood to receive the stories of the sites. The sound of a heartbeat at the end of the logo is a 'sticky sound' that has strong potential to sensitize the receiver to the affectivity of the videos.

The stories in the videos are given an audible rhythm by the interplay between the narrator's voice and classical music, which at times sinks into the background of the narrator's voice but rises to the fore whenever there is a break in the narrator's talk. The classical music has the role of a 'sticky sound' in the videos, since it effectively creates a sensitive atmosphere and thus strengthens the impact of the textual, visual, and narrative tropes recurring in the videos.

\section{Narrative Tropes}


Narration is a crucial element in the sense-making of heritage; the idea and status of heritage is attached to places, objects, and intangible phenomena through narrativization (Lähdesmäki 2014). The textual, visual, and audible elements create in each video a lively story that crystallizes the key historical phases of the site and explains its significance as a European cultural heritage. The stories end with an explicit or implicit lesson for present-day Europe and/or a juxtaposition of the attempts and achievements taken place at the site in the past and those of the EU in the present. Even though the contents of the stories in the videos vary, most of them share a common narrative trope: a struggle and an effort by local people or certain key figures leads to conciliation and/or a major positive change. When told with affective textual, visual, and audible elements, this kind of narrative trope easily becomes emotionally charged.

The 'sticky narratives' in the videos commonly stem from the struggles of war and thus bring to the fore the most 'moving' topics: life and death. For example, in the video of the Franja Partisan Hospital, the story draws together the topics of violence, the agony of the victims of WWII, human encounters, and altruistic helping of the wounded:

The path to the hospital runs along a stream which flows through the gorge. By this path, all the wounded were transported at night because safety reasons. The hospital was never discovered during the war. Civilians cooperated together, they all collected food, medicine. Almost 900 wounded were treated in the hospital — not only Slovenian partisans, but also Russians, Poles, French, Austrians, Americans. Solidarity, comradeship, humanity, they were not just words for those people. (1:49-2:35)

Encountering people in a time of struggle is a common element of the 'sticky narrative' recurring in the videos. This element is typically used in the videos that underline attempts at peace that have taken place at the site. Negotiation, dialogue, and solidarity are brought to the fore as key forms of encountering other people.

Heroism is a topic that has the potential to touch people at the affective level. The affectivity of heroism has been long utilized in diverse territorial and political projects and in entertainment industries ranging from romantic novels to superhero movies. The emphasis of 'great deeds' done either by individuals or a group of civilians is a recurring element of the 'sticky narratives' in the videos. These great deeds are told as crucial turning points of history with a major positive impact on people, communities, societies, and/or Europe as a whole. When an individual does 
a great deed, the story creates a mythical hero, such as in the case of the video of Robert Schuman's House. The narrator in the video says:

This office is where, at the end of April 1950, Robert Schuman comes to take a few days rest. He opens his briefcase and reads the letter that Jean-Monnet gave him a few hours earlier at Gare de l'Est in Paris. This is where he draws up the first version of the 9 May speech and where Europe was born. He witnessed the consequences of WWI, the rise of nationalism between the two wars, and he witnessed the Second World War. And it's all of this historical background which led him to say in 1945 , 'We must change the way we treat our enemies, because the enemy, Germany, has lost the war'. Schuman argued for no longer saying, 'They're an enemy', but insisted, 'We will be allies, we will reach out to this nation and build relations'. (1:16-2:04)

In this case, the story is enlivened by using the historical present tense and emphasizing the authenticity of the story by visualizing it with 'real' objects and environments mentioned by the narrator. The story creates a hero by bringing to the fore his heroic deed: the emergence of Europe. The vocabulary used in the story unproblematically parallels the idea of Europe and the European Union. Schuman's heroic deed is contextualized in the video by combining the topics of war and a struggle for peace and reconciliation in the story.

Stories about great deeds easily take on noble and sublime tones, particularly when they include topics of a serious danger or threat, the superiority of the enemy, unity and solidarity between oppressed people, and a struggle for justice. The video of The Historic Gdańsk Shipyard (Poland) crystallizes these narrative elements:

This is a place where, for the first time, world saw that some unknown workers from Gdansk are fighting not for their interests but for civil rights, for universal rights.

We were faced with great danger. There were 200,000 Soviet soldiers in Poland, and more than a million in surrounding countries. There were silos with nuclear weapons. We were rejecting the whole Communist system. We helped to draw many countries out of Soviet domination. It was probably Europe's first and biggest victory, using new methods. (0:58$1: 41)$

The affectivity of the story is emphasized by using the key witness and main hero of the story, Lech Wałęsa, as its narrator; he contributes to the story from the first-person-plural point of 
view. The 'new methods' of the victory in the story bring to the fore the trope of reconciliation and encounter. As Wałęsa says in the video: 'We showed that the biggest problems should be solved at the negotiating table, they should be solved in the intelligent way, using arguments rather than force.' $(3: 08-3: 21)$

\section{EU Policy Tropes in the Meaning-Making of a European Cultural Heritage}

The poetic dimension of EU policy discourse is manifested in the emphasis on various values, ideals, and political principles that are seen as the basis of the union and as the key elements the union seeks to promote through its politics and policies. This 'value rhetoric' extends from the fundamental treaties of the union, such as the Treaty of Lisbon, to decisions of action in difference policy sectors of the Commission, such as initiatives in culture and heritage. The decision on the European Heritage Label argues for action as follows:

For citizens to give their full support to European integration, greater emphasis should be placed on their common values, history and culture as key elements of their membership of a society founded on the principles of freedom, democracy, respect for human rights, cultural and linguistic diversity, tolerance and solidarity. (EC 2011, 1)

The application form for the label advises candidates to describe to what extent the site has contributed to the development and/or promotion of the values mentioned in Article 2 of the Treaty on the European Union. According to it:

the Union is founded on the values of respect for human dignity, freedom, democracy, equality, the rule of law and respect for human rights, including the rights of persons belonging to minorities. The values are common to the Member States in a society in which pluralism, non-discrimination, tolerance, justice, solidarity and equality between women and men prevail. (EC 2015)

The above-mentioned values, ideals, and political principles are discussed in this section as tropes of EU policy rhetoric. Next, my analysis focuses on identifying these policy tropes from the data and exploring how the policy tropes are connected to the affective textual, visual, audible, and narrative tropes recurring in the videos. The close relation between these tropes indicates how politics is intertwined in the affectivity of the videos and how affect becomes politics and politics affective. 
The most repeated EU policy tropes in the videos are 'peace/peaceful' (occurring 26 times), 'democracy/democratic' (9), 'law' (7), 'free/freedom' (6), 'unity/united' (5), 'rights' (4), 'cooperation' (4), ‘tolerance' (4), and 'solidarity' (4). In addition, various single expressions and topics used in the videos, such as a 'European dimension', 'signing an agreement', 'making accessible', 'trade across Europe', 'establishing connections', 'creating a constitution', and 'cross-border and multicultural experience', connect the stories of the sites to EU policy discourse. In six videos, the narrators specifically name some common European values. These are: peace and objection to war, the process of mediation in conflicts, democracy, freedom of movement of goods and persons, solidarity, tolerance through dialog, comradeship, humanity, participation, and encountering people with difference backgrounds. This list of European values reflects the list repeated in EU policy discourse.

Besides these EU policy tropes, the narrative tropes in the videos circulate common elements from EU policy discourse. The stories of the sites are commonly told by emphasizing the narrative elements that the EU uses in its description of the 'European project'. Thus, in the videos the historical events taken place at the site and the ideas and achievements connected to them are explicitly or implicitly paralleled with those of the EU. The explicit paralleling gives a positive historical context to the EU's political attempts and policies and produces a historical continuity between the EU and historical events that may reach far back into the past, as the narrator's speech in the video of the Archaeological Park Carnuntum (Austria) demonstrates:

We could learn a lot from the Romans. Even if it was 2000 years ago, it looks to us very actual, because the achievements of the Romans are very actual today. They talked about the freedom of movement, of goods and persons, which is one of the core values of the European Union. Look at the Roman system of justice. It's the basis for all modern justice systems. Or look at the Latin language, which is the basis of many European languages. $(2: 41-3: 19)$

Particularly, the idea of peaceful unification and active cooperation between different European nations forms a topic that is presented as binding together the European past and the present political reality of the EU. For example, the story in the video of the Union of Lublin narrates the historical union between the Kingdom of Poland and the Grand Duchy of Lithuania as a predecessor of the EU. Besides explicitly juxtaposing the European past and present EU policies, many of the videos compare past events that occurred at the sites to those currently 
taking place in Europe. In these stories, 'Europe', however, commonly refers to the EU. The linkage of the story of the site to the EU can also be done through visual elements. For example, the video of the Peace Palace (The Netherlands) ends with the narrator's words: 'The peace conference I spoke about, of 1899, was [about] the European nations and a few around it; and I think even nowadays you can see that the whole concept of Europe is built on the idea of peaceful coexistence of partners' (2:52-3:09). The speech is visualized by the gilded name and dates of the birth and death of Jean Monnet, the key 'founding father' of the EU, on the side of a marble pedestal and a close-up of the face of his bronze statue, and after these images showing the name of Erasmus on the side of a pedestal and a mid-shot of his bronze statue. The juxtaposition of these two figures uplifts the role of the so-called founding fathers of the EU as common European 'great men' and establishes their role in European history.

\section{Conclusions: Workings of Affect and the Irrefutability and Choicelessness of Politics}

The videos of the European Heritage Label sites draw to the fore various social and societal virtues as common cultural roots of Europeans and as a moral legacy to be fostered and promoted in today's Europe. The ethos of a European cultural heritage in the videos is based on a paradox: the history of the several sites is in various ways intertwined with extreme agony, violence, hatred, oppression, and injustice. However, the stories of the sites in the videos turn their legacy into a positive ethos of conquering these negative extremes and cherishing their positive opposites: freedom, justice, solidarity, and peace. The European heritage is portrayed in the videos as a 'victory' of various virtues brought about by various visionary 'heroes' and far-reaching heroic deeds. The intertwined nature of the extreme good and bad and the heroic deeds turning the bad into good calls to the fore sublimity and pathos in the idea of heritage. In the videos, the sublime nature of these extremes is strengthened by their estheticization. Classical music, beautiful landscape scenes, photographic images of nature, works of art, and impressive architectural spaces conduct the stories of the sites, which are intertwined with struggle, war, and violence while also estheticizing their representations.

The videos include various affective elements that have the potential to generate pathos and sublimity in the receivers. Pathos and sublimity invoked by heritage are 'easy' emotions, since they are generally culturally acceptable - and even expected. Feeling the 'greatness' of significant heritage sites and appreciating their historical, cultural, and artistic magnitude is a 
common discourse in the Western world-resonating even with the rhetoric of the UNESCO World Heritage Listing. Similarly, feeling pathos needs no justification or explanation; mourning over wasted lives, admiration of self-sacrifice, and gratitude for 'our' heroes are commonly expected cultural-moral norms (cf. Rumi 2015).

The power of affect lies in its capacity to generate resonance and 'move' regardless of the ideological content of its producer. Indeed, the consciously received 'message' may, and often does, leave less of an impression on the receiver than his/her affective resonance with the source of the message (Mikula 2008). In the videos of the European Heritage Label sites, various textual, visual, audible, and narrative tropes are intertwined with EU policy tropes, also making EU policy discourse affective and thus increasing its capacity to impact and 'move' the receivers. This crystallizes the politics of affect in the videos: the affective level of the videos seeks to make the receivers adopt its message-support for the Commission's European project - on their own initiative, although they might object to it at the cognitive level.

Although the narrators in the videos are local experts, the stories of the sites are narrated from the point of the view of EU politics and policy. The short length of the stories in the videos inevitably simplifies the complexity of the history of the sites, thus leaving to the affective elements used in the videos a crucial role of compensating and broadening the story. The truthfulness of these stories may be difficult for the receivers to assess-but their affectivity certainly invokes 'emotional truths' (cf. Campbell 2006; Smith and Campbell 2015) that do not require minute details, but rather capture the salience of contexts and rely on the appropriateness and fit of the story in the assessment of its truthfulness.

The politics of affect in the videos stems from the capacity to produce 'emotional truths' that are not based only or even primarily on their historical accuracy, but rather on their moral appropriateness and fit. The values, ideals, and political principles emphasized in the videos, such as peace, democracy, justice, and solidarity, are social and societal virtues. It would be morally unjustifiable to object to them or to deny their importance. Indeed, the videos utilize a strategy that can be called the 'politics of irrefutability': the validity of the message of the videos is irrefutable. It is difficult to question the virtues that are presented in the videos as universal and choiceless solutions to problems, as the narrator in the video of The Heart of Ancient Athens (Greece) states: 'Participation is the only way to cope with our problems, and this is the message sent all over the world by the ancient Athenian democracy. The values it incorporates are very 
modern, they even surpass our modernity' (2:00-2:20). These kinds of expressions make the message of the videos choiceless, emphasizing at the same time the inevitable nature of EU politics and policy as the basis of this message.

As the analysis of the videos indicates, affect has a key role in the production of a feeling and an impression of the irrefutability and choicelessness of EU politics. The affectivity of the videos is a means of politics that aims to 'move' and effect subjects non-cognitively, but also to create a cognitive response. Affect does not only engage individuals; it works to align individuals and collectives (Ahmed 2004b). Affect as a trans-personal phenomenon, therefore, participates in the formation of collectives. The fundamental aim of EU cultural policy in general, and EU heritage initiatives in particular, is to invoke in Europeans a feeling of belonging to Europe and the EU, a sense of communality among Europeans, and a European identity. Affectivity and emotiveness have a central role in cultivating a sense of belonging (Yuval-Davis 2006; Guibernau 2011). As Guibernau (2011, 28-29) notes, belonging fosters an emotional attachment that 'prompts the expansion of the individual's personality to embrace the attributes of the group, to be loyal and obedient to it'. A European identity as the EU's political project aims exactly at this: to create loyal members of EU Europe whose European identity is based on an amalgam of shared heritage, cultural roots, collective memory, values, ideals, political principles, and emotional attachments.

Through its identity politics the EU seeks to respond to various current crises, conflicts, and challenges in Europe, such as Europeans' growing skepticism and disenchantment with the EU and its European project. The EU seeks to contest the Eurosceptic and anti-EU views of rightwing populist and new nationalist parties and movements with the same means that are commonly used by these parties and movements - by mobilizing affect as an instrument of politics. In this contest, the EU is an underdog - and a lack of a common European public sphere does not make its position and efforts any easier.

\section{Acknowledgements}

This work was supported by the Academy of Finland under Grant SA274295 (EUCHE) and the European Research Council (ERC) under the EU's Horizon 2020 research and innovation program under Grant 636177 (EUROHERIT). 
Notes

1 The italics are used in the quotations of this section to emphasize the affective words, 'figures of speech', or expressions identified in the close reading.

2 Quotations include mistakes as English is not speakers' native language.

\section{References}

Ahmed, S. 2004a. The Cultural Politics of Emotion. London: Routledge.

Ahmed, S. 2004b. "Collective Feelings: Or, the Impressions Left by Others." Theory, Culture and Society 21 (2): $25-42$.

Ahmed, S. 2004c. “Affective Economies.” Social Text 79 (2): 117-139.

Bagnall, G. 2003. "Performance and Performativity at Heritage Sites." Museum and Society 1 (2): 87-103.

Banús, E. 2015. Keynote speech in the 13th International Conference European Culture, ClujNapoca, Romania, October.

Blackman, L. and C. Venn. 2010. “Affect.” Body \& Society 16 (1): 7-28.

Brennan, T. 2004. The Transmission of Affect. London: Cornell University Press.

Brummet, B. 2010. Techniques of Close Reading. London: Sage.

Campbell, S. 2006. "Our Faithfulness to the Past: Reconstructing Memory Value." Philosophical Psychology 19 (3): 361-380.

Connolly, W. E. 2002. Neuropolitics: Thinking, Culture, Speed. Minneapolis: University of Minnesota Press. 
Crang, M. and D. P. Tolia-Kelly. 2010. "Nation, Race, and Affect: Senses and Sensibilities at National Heritage Sites.” Environment \& Planning A 42 (19): 2315-2331.

Deleuze, G. 1997. Essays Critical and Clinical. (D.W. Smith \& M.A. Grego, Trans.). Minneapolis: University of Minnesota Press.

EC 2011. Decision no 1194/2011/EU of the European Parliament and of the Council of 16 November 2011 establishing a European Union action for the European Heritage Label. Official Journal of the European Union L 303: 1-9.

EC 2015. European Heritage Label, application form. Brussels: European Commission.

EC 2016. Discover the Sites. Web site of the European Commission. Retrieved from https://ec.europa.eu/programmes/creative-europe/actions/heritage-label/sites_en

Gregory, K. and A. Witcomb. 2007. "Beyond Nostalgia: The Role of Affect in Generating Historical Understanding at Heritage Sites." In Museum Revolutions: How Museums Change and are Changed, edited by S. J. Knell, S. Macleod and S. Watson, 263-275. Abingdon: Routledge.

Golańska, D. 2015. “Affective Spaces, Sensuous Engagements: In Quest of a Synaesthetic Aapproach to 'Dark Memorials'.” International Journal of Heritage Studies 21 (8): 773-790.

Grossberg, L. 1992. We Gotta Get Out of This Place: Popular Conservatism and Postmodern Culture. London: Routledge.

Grossberg, L. 1997. Dancing in spite of Myself: Essays on Popular Culture. Durham: Duke University Press.

Guibernau, M. 2013. Belonging: Solidarity and Division in Modern Societies. Cambridge: Polity Press. 
Jewitt, C., and R. Oyama. 2001. "Visual Meaning: A Social Semiotic Approach.” In

Handbook of Visual Analysis, edited by T. van Leeuwen and C. Jewitt, 134-156. London:

Sage.

Kølvraa, C. 2015. “Affect, Provocation, and Far Right Rhetoric.” In Affective Methodologies.

Developing Cultural Research Strategies for the Study of Affect, edited by B. T. Knudsen and

C. Stage, 183-200. Basingstoke: Palgrave Macmillan.

Kress, G. 2003. Literacy in the New Media Age. London: Routledge.

Kress, G., and T. van Leeuwen. 2006. Reading Images: The Grammar of Visual Design.

London: Routledge.

Lähdesmäki, T. 2014. "Transnational Heritage in the Making. Strategies for Narrating Cultural Heritage as European in the Intergovernmental Initiative of the European Heritage Label." Ethnologica Europaea 44 (1): 75-93.

Lähdesmäki, T. 2015. "The Ambiguity of Europe and European Identity in Finnish Populist Political Discourse.” Identities: Global Studies in Culture and Power 22 (1): 71-87.

Laurier, E. and C. Philo. 2006. "Possible Geographies: A Passing Encounter in a Café." Area 38 (4): 353-363.

van Leeuwen, T. 2005. Introducing Social Semiotics. New York: Routledge.

Littoz-Monnet, A. 2012. "The EU Politics of Remembrance: Can Europeans Remember Together?" West European Politics 35 (5): 1182-1202.

Liu, J. 2013. "Visual Images Interpretive Strategies in Multimodal Texts.” Journal of Language Teaching and Research 4 (6): 1259-1263.

Mikula, M. 2008. Key Concepts in Cultural Studies. Basingstoke: Palgrave Macmillan. 
O'Sullivan, S. 2001. "The Aesthetics of Affect: Thinking Art beyond Representation." Angelaki 6 (3): 125-135.

O'Sullivan, S. 2006. Art Encounters Deleuze and Guattari. Thought Beyond Representation. Basingstoke: Palgrave Macmillan.

Poria, Y. 2007. "Establishing Cooperation between Israel and Poland to Save Auschwitz Concentration Camp: Globalising the Responsibility for the Massacre." International Journal of Tourism Policy 1 (1): 45-57.

Poria, Y., R. Butler, and D. Airey. 2003. "The Core of Heritage Tourism.” Annals of Tourism Research 30 (1): 238-254.

Pruchnic, J. and K. Lacey. 2011. "The Future of Forgetting: Rhetoric, Memory, Affect." Rhetoric Society Quarterly 41 (5): 472-494.

Reddy, W. M. 2001. The Navigation of Feeling: A Framework for the History of Emotions. Cambridge: Cambridge University Press.

Riley, D. 2005. Impersonal Passion: Language as Affect. Durham: Duke University Press.

Rumi, S. 2015. "Mobilizing Affect for Collective War Memory.” Cultural Studies 29 (2): $158-184$.

Sassatelli, M. 2015. "Narratives of European Identity." In European Cinema and Television. Cultural Policy and Everyday Life, edited by I. Bondebjarg, E. N. Redvall and A. Higson, 2542. Basingstoke: Palgrave Macmillan.

Sedgwick, E. K. 2003. Touching Feeling: Affect, Pedagogy, Performativity. Durham: Duke University Press.

Smith, L. 2011. "Affect and Registers of Engagement: Navigating Emotional Responses to Dissonant Heritages." In Representing Enslavement and Abolition in Museums: Ambiguous 
Engagements, edited by L. Smith, G. Cubitt, R. Wilson and K. Fouseki, 260-303. London: Routledge.

Smith, L. 2015. "Theorizing Museum and Heritage Visiting." The International Handbooks of Museum Studies 3 (22): 459-484.

Smith, L. and G. Campbell. 2015. "The Elephant in the Room: Heritage, Affect and Emotion.” In A Companion to Heritage Studies, edited by W. Logan, M. Nic Craith and U. Kockel, 443-460. London: Wiley-Blackwell.

Smith, L. and E. Waterton. 2009. Heritage, Communities and Archaeology. London: Duckworth.

Smith, R. G. 2015. Affect and American Literature in the Age of Neoliberalism. New York: Cambridge University Press.

Soren, B. J. 2009. "Museum Experiences that Change Visitors.” Museum Management and Curatorship 24 (3): 233-251.

Thompson, M. and L. Biddle. 2013. "Introduction: Somewhere between the Signifying and the Sublime." In Sound, Music, Affect: Theorizing Sonic Experience, edited by M. Thompson and I. Biddle, 1-24. London: Bloomsbury Publishing.

Thrift, N. 2008. Non-Representational Theory: Space, Politics and Affect. London: Routledge.

Waterton, E. 2014. "A More-Than-Representational Understanding of Heritage? The 'Past' and the Politics of Affect." Geography Compass 8 (11): 823-833.

Waterton, E. and S. Watson 2013. "Framing Theory: Towards a Critical Imagination in Heritage Studies.” International Journal of Heritage Studies 19 (6): 546-561. 
Waterton, E. and S. Watson. 2015. "Methods in Motion: Affecting Heritage Research." In Affective Methodologies. Developing Cultural Research Strategies for the Study of Affect, edited by B. T. Knudsen and C. Stage, 97-118. Basingstoke: Palgrave Macmillan.

Wetherell, M. 2012. Affect and Emotion: A New Social Science Understanding. London: Sage.

Wetherell, M. 2013. "Affect and Discourse - What's the Problem? From Affect as Excess to Affective/Discursive Practice." Subjectivity 6 (4): 349-368.

Yuval-Davis, N. 2006. "Belonging and the Politics of Belonging." Patterns of Prejudice 40 (3): 197-214. 